carcinoma of the oesophagus, breast, bladder, kidney, and thyroid (table IV). These results were not negligible because some of the tumours, such as cancers of the bladder, the kidney (fig. 3), and the thyroid (fig. 4), were insensitive to the available chemotherapeutic agents. Bladder carcinoma had been previously shown by us to be sensitive to VM 26 (E.O.R.T.C., 1972). Three of the tumours which regressed were in the pleura. That again suggests that VP 16213 as well as VM 26 may have a special affinity for mesothelia. There were 15 deaths among the patients with solid tumours. Only one of the deaths was due to chemotherapy.

\section{Discussion}

Epipodophyllotoxin VP 16213 represents an advance in the treatment of acute monocytoid leukaemia, which has been insensitive to any drug up till now (Mathé and Kenis, 1973). This is also true for acute myelomonocytoid leukaemia, in which it was often impossible to obtain a complete remission in some patients because of the persistence of monocytoid cells in the blood despite the sensitivity of the myeloid cells to cytosine arabinoside (fig. 3) (Mathé et al., 1973). VP 16213 also seems to be effective in bladder, kidney, and thyroid carcinomas, against which the available drugs were currently doing very badly (except VM 26 for bladder cancer). The Urology Cooperative Group of E.O.R.T.C. is to conduct further phase II or phase III trials of VP 16213 in the treatment of bladder cancers, with more patients under different conditions.

VP 16213 exercises some effect on cases of reticulosarcoma, Hodgkin's disease, melanoma, and carcinoma of breast and ovary, for which there are other active drugs. Thus operational trials will be conducted by the different Co-operative Groups of E.O.R.T.C. in these areas.

\section{VP 16213 was supplied by Sandoz Laboratory.}

Requests for reprints should be addressed to: Institut de Cancerologie et d'Immunogenétique, Hôpital Paul-Brousse, 14-16 avenue Paul-Vaillant Couturier, 94800-Villejuif, France.

\section{References}

E.O.R.T.C., Co-operative Group for Leukaemias and Haematosarcomas (1972). British Medical Fournal, 2, 744.

Mathé, G., and Kenis, Y., (1973). La Chimiothérapie des Cancers (Leucémies, Hématosarcomes et Tumeurs Solides) à l'Usage du Praticine, 3rd edn. vol. 1 . Paris, Expansion Scientfique Française. In press.

Mathé, G., Pouillart, P., Hayat, M., Steresco, M., and Lafleur, M. (1973) In Acute Leukemias Nomenclature, Classification, Clinical Trials, Methodology and Actuarial Results, ed. G. Mathe, P. Pouillart and L. Schwodology and Actuarial Results, ed. G. Mathe, P. Pot

Stahelin, H. (1970). European fournal of Cancer, 6, 211.

\title{
Abdominal Bruit after Renal Transplantation
}

\author{
S. J. JACHUCK, R. WILKINSON
}

British Medical fournal, 1972, 3, 202-203

\section{Summary}

Forty-seven recipients of renal allografts have been studied at varying intervals of up to five years after transplantation. Renal artery bruit occurred in eight of 16 patients observed over the first two post-transplant months and disappeared spontaneously in four of these. The disappearance of the bruit was associated with poor renal function. Renal bruits were audible in 10 patients examined more than two months after transplantation; nine of these were hypertensive and of six in whom arteriography was performed five were shown to have stenosis of the allograft artery. By contrast only eight of 37 patients without abdominal bruit were hypertensive, and arteriography in 10 normotensive patients without bruit showed no stenosis. It is concluded that while a renal artery bruit during the first two months after transplantation may be a marker of good renal blood flow at the time, its presence suggests a poor long-term prognosis since persistence of the murmur indicates that significant stenosis of the allograft artery is likely, while its disappearance is associated with poor renal function.

\footnotetext{
Department of Medicine, Newcastle University Medical School and Newcastle University Hospitals, Newcastle upon Tyne NE4 6BE S. J. JACHUCK, B.sC., M.B., Registrar Physician

R. WILKINSON, M.B., M.R.C.P., Consultant Physician and Senior Lecturer
}

Introduction

Abdominal bruit is a useful clinical sign in the diagnosis of renovascular hypertension (Simon et al., 1972). In renal transplant recipients bruits over the allograft renal artery have been regarded on the one hand as a sign of narrowing of the artery (Kincaid-Smith et al., 1969), and on the other as a sign of good renal perfusion (Braun, 1972; Anderson et al., 1973). This conflicting evidence on the significance of arterial bruits prompted us to review our surviving renal transplant recipients in order to determine the relation of bruit to hypertension and to graft function.

\section{Patients and Methods}

Forty-seven recipients of renal allografts were studied from two to 60 months after transplantation. Sixteen of these patients were also studied during the first eight postoperative weeks. In 26 patients the donor was a relative, in the remaining 21 cadaver kidneys were used.

Blood pressure was recorded in the supine position and hypertension defined as a persistently raised diastolic blood pressure above $100 \mathrm{~mm} \mathrm{Hg}$. Abdominal auscultation was carried out in the mid-line above and below the umbilicus, over the medial border of the transplanted kidney, and over the femoral arteries.

Selective arteriography of the allograft artery was performed in seven patients because of hypertension and in 10 without hypertension or rejection as part of a separate study.

In those 16 patients observed over the first eight weeks after transplantation daily blood counts and renal function tests were performed as well as clinical assessment for evidence of 
rejection until stable renal function was established. Thereafter, assessment was twice weekly up to eight weeks and then at increasing intervals in all patients depending on the stability of function.

\section{Results}

\section{SITE OF BRUIT}

The abdominal bruits were systolic in time and not transmitted from the heart. The sites at which bruits were heard are shown in table I. The medial aspect of the transplanted kidney was the commonest situation.

TABLE I-Location of Abdominal Bruits in Transplant Recipients

\begin{tabular}{lllllllll}
\hline $\begin{array}{l}\text { Medial to graft } \\
\text { Over femoral artery }\end{array}$ & $\ldots$ & $\ldots$ & $\ldots$ & $\ldots$ & $\ldots$ & $\ldots$ & $\ldots$ & No. of Cases \\
Both graft and femorai & $\ldots$ & $\ldots$ & $\ldots$ & $\ldots$ & $\ldots$ & $\ldots$ & $\mathbf{1}$ \\
\hline
\end{tabular}

\section{HYPERTENSION AND BRUIT}

The relation between hypertension and the presence of abdominal bruit showed that while nine of the 10 patients with a bruit were hypertensive, only eight of 37 without bruit had raised blood pressure.

\section{ANGIOGRAPHY}

The results of allograft angiography in the seven patients with severe hypertension and persistent abdominal bruit subjected to this procedure are shown in table II. In this group the incidence of arterial stenosis is high. However, patients with bruit and lesser degrees of hypertension have not been subjected to arteriography, so we cannot be certain of the significance of bruit in all cases. In 10 normotensive patients without abdominal bruit arteriography showed no vascular stenosis.

TABLE II-Results of Angiography in Seven Patients with Hypertension and Bruit

\begin{tabular}{lllllllc}
\hline & & & & & & & No. of Patients \\
Stenosis of allograft artery & $\ldots$ & $\ldots$ & $\ldots$ & $\ldots$ & $\ldots$ & $\ldots$ & 5 \\
$\begin{array}{l}\text { Normal allograft artery } \\
\text { Widespread atheroma }\end{array}$ & $\ldots$ & $\ldots$ & $\ldots$ & $\ldots$ & $\ldots$ & $\ldots$ & 1 \\
\hline
\end{tabular}

\section{EARLY BRUIT}

Of the 16 patients studied in the early post-transplant period eight developed abdominal bruit. This appeared within the first 48 hours and in four patients it disappeared during the ensuing eight weeks. Arteriography was performed in two of the four patients in whom bruit persisted beyond eight weeks and in both cases showed stenosis of the allograft artery.

At the time of appearance of the bruit all 16 patients were anaemic. The mean haemoglobin on the day after transplantation in those with bruit was $9 \cdot 2 \mathrm{~g} / 100 \mathrm{ml}$ (S.D. 1.12) and in those without bruit $9.0 \mathrm{~g} / 100 \mathrm{ml}$ (S.D. 1.58) - the difference was not significant $(P>0.35)$. At two months after transplant the mean haemoglobin had risen in both the original bruit and non-bruit groups to 10.3 (S.D. 1.79) and 10.0 (S.D. 2.5$) \mathrm{g} / 100 \mathrm{ml}$ respectively; again the difference was not significant $(P>0.35)$. The mean haemoglobin in the four patients in whom bruit persisted was $11.35 \mathrm{~g}$ while in the four in whom bruit disappeared it was $9 \cdot 3 \mathrm{~g} / 100 \mathrm{ml}$.

The mean level of serum creatinine in patients in whom a bruit had been heard at some stage was $3.35 \mathrm{mg} / 100 \mathrm{ml}$ (S.D. 3.0 ) and in those without bruit $3.27 \mathrm{mg} / 100 \mathrm{ml}$ (S.D. 2.89) - the difference was not significant $(P>0 \cdot 475)$. However, in those four patients in whom a murmur was initially heard but later disappeared the mean serum creatinine was $5.2 \mathrm{mg} / 100 \mathrm{ml}$ compared with $1.5 \mathrm{mg} / 100 \mathrm{ml}$ in those in whom the bruit persisted.

\section{Discussion}

Arterial bruits are produced by turbulent flow, which may be induced by irregularity or stenosis of the vessel or by increased flow within the vessel especially when this is accompanied by decreased blood viscosity (Wales and Martin, 1963).

\section{EARLY BRUIT}

An arterial bruit was audible over the transplanted kidney in half of our patients in the early postoperative period. This could not be explained by the presence of anaemia since those with bruit were not more anaemic than those without. Furthermore the bruit disappeared in three of the patients despite a slight reduction in haemoglobin level. It is possible that initial irregularity at the anastomotic site becoming smooth as epithelialization proceeds accounts for the early murmurs which do not persist. Though the number of patients is too small for valid statistical analysis, however, it appears that disappearance of the bruit may be associated with increasing serum creatinine, suggesting that the murmur may be an indicator of good renal blood flow and its disappearance may reflect reduction in renal blood flow. Though absence of a bruit is by no means incompatible with good renal function the disappearance of an established murmur may herald worsening renal function. These results are broadly in agreement with those of Anderson et al. (1973), who found patients with persistent bruit to have the best renal function and those in whom an early bruit disappeared to have the worst. Braun (1972) also found that the presence of a bruit indicated good renal function.

\section{LATE BRUIT}

Though the finding of a bruit in the early post-transplant period was often associated with good renal function, we found that a bruit persisting more than two months after transplantation was usually accompanied by hypertension.

In those patients with bruit subjected to arteriography stenosis of the allograft artery was usually found. These findings are in accord with those of Morris and his colleagues (1971). We cannot comment on the likely incidence of allograft arterial stenosis in those patients with hypertension without renal bruit since we did not routinely perform arteriography in the absence of bruit. However, we did find renal artery stenosis in one patient with hypertension without bruit. No normotensive patients were found to have stenosis of the renal artery. This association of bruit with hypertension and allograft artery stenosis was not reported by Anderson et al. (1973) in their series of patients, but examination of their data shows that eight of their nine hypertensive patients had persisting renal bruit.

We therefore conclude that though the presence of a bruit over the transplanted kidney in the early postoperative period may be an indicator of good renal blood flow, the finding suggests a poor long-term prognosis. The disappearance of the bruit is usually accompanied by worsening renal function, and a persistent murmur is almost invariably a sign of stenosis of the graft artery sufficient to cause hypertension.

We are grateful to Professor D. N. S. Kerr and Dr. P. R. Uldall for their help in this study. We would also like to thank Professor J. Swinney, Mr. R. M. R. Taylor, and Mr. R. W. G. Johnson who performed the transplant operations, and the staff of the renal unit for their co-operation.

\section{References}

Anderson, C. F., et al. (1973). Mayo Clinic Proceedings, 48, 13. Braun, W. E. (1972). New England fournal of Medicine, 286, 1350. Kincaid-Smith, P., Hare, W. S. C., Morris, P. J., and Marshall, V. C. (1969). Proceedings of European Dialysis and Transplant Association, 6, 235

Morris, P. J., et al. (1971). Medical fournal of Australia, 1, 1255.

Simon, N., Franklin, S. S., Bleifer, K. H., and Maxwell, M. H. (1972). Fournal of the American Medical Association, $220,1209$.

Wales, R. T., and Martin, E. A. (1963). British Medical fournal, 2, 1444.

\section{.} .

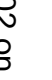

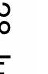

